\title{
Advanced glycation end-products (AGEs) and functionality of reverse cholesterol transport in patients with type 2 diabetes and in mouse models
}

\author{
H. Low • A. Hoang • J. Forbes • M. Thomas • \\ J. G. Lyons • P. Nestel • L. A. Bach • D. Sviridov
}

Received: 24 January 2012 / Accepted: 5 April 2012 / Published online: 10 May 2012

(C) Springer-Verlag 2012

\begin{abstract}
Aims/hypothesis We investigated the contribution of AGEs to the impairment of reverse cholesterol transport (RCT) variables in diabetic individuals and in two animal models of diabetic obesity and of renal impairment.

Methods The capacity of plasma and HDL from 26 individuals with moderately controlled type 2 diabetes to support cholesterol efflux was compared with 26 age- and sexmatched individuals without diabetes. We also compared the rates of RCT in vivo in two animal models: $d b / d b$ mice and mice with chronic renal failure.

Results Diabetic individuals had characteristic dyslipidaemia and higher levels of plasma AGEs. The capacity of whole plasma, ApoB-depleted plasma and isolated HDL to
\end{abstract}

H. Low and A. Hoang contributed equally to this study.

Electronic supplementary material The online version of this article (doi:10.1007/s00125-012-2570-9) contains peer-reviewed but unedited supplementary material, which is available to authorised users.

H. Low $\cdot$ A. Hoang $\cdot$ J. Forbes $\cdot$ M. Thomas $\cdot$ J. G. Lyons $\cdot$

P. Nestel $\cdot$ D. Sviridov $(\bowtie)$

Baker Heart and Diabetes Institute,

PO Box 6492, St Kilda Road Central,

Melbourne, VIC 8008, Australia

e-mail: Dmitri.Sviridov@bakeridi.edu.au

\section{A. Bach}

Department of Medicine, Monash University,

Melbourne, VIC, Australia

L. A. Bach

Department of Endocrinology and Diabetes, Alfred Hospital,

Melbourne, VIC, Australia

D. Sviridov

Department of Biochemistry and Molecular Biology,

Monash University,

Melbourne, VIC, Australia support cholesterol efflux was greater for diabetic patients compared with controls despite their lower HDL-cholesterol levels. The capacity of plasma to support cholesterol efflux correlated with plasma levels of cholesteryl ester transfer protein and levels of ApoB, but not with levels of AGE. RCT was severely impaired in $d b / d b$ mice despite elevated HDL-cholesterol levels and no change in AGE concentration, whereas RCT in uraemic mice was unaffected despite elevated AGE levels.

Conclusions/interpretation AGEs are unlikely to contribute significantly to the impairment of RCT in type 2 diabetes.

Keywords AGE - Cholesterol · Diabetes · HDL .

Reverse cholesterol transport

$\begin{array}{ll}\text { Abbreviations } \\ \text { ABC } & \text { ATP binding cassette transporters } \\ \text { ApoA-I } & \text { Apolipoprotein A-I } \\ \text { CETP } & \text { Cholesterol ester transfer protein } \\ \text { CML } & \text { Carboxymethyl lysine } \\ \text { LCAT } & \text { Lecithin:cholesterol acyl transferase } \\ \text { LPDP } & \text { Lipoprotein-deficient plasma } \\ \text { LXR } & \text { Liver X receptor } \\ \text { PLTP } & \text { Phospholipid transfer protein } \\ \text { RCT } & \text { Reverse cholesterol transport }\end{array}$

\section{Introduction}

Type 2 diabetes increases the risk of coronary heart disease two- to fourfold [1]. The increased risk of atherosclerosis in diabetes is multi-factorial with dyslipidaemia considered one of the most important atherogenic factors [2, 3]. It is clear that there are diabetic-specific lipid-related factors that contribute to the development of diabetes-induced 
atherosclerosis in addition to diabetes-induced changes in the plasma lipoprotein profile.

Diabetes-related changes in cholesterol metabolism may be critical for diabetes-induced atherosclerosis. Diabetesinduced changes in the forward transport branch of lipoprotein metabolism have been investigated [2], but knowledge about the characteristics of HDL and its relationship to reverse cholesterol transport (RCT) is limited. Several elements of RCT are affected by diabetes. For example, HDL levels are consistently low in patients with type 2 diabetes [4] and activities of lecithin:cholesterol acyl transferase (LCAT) [5] and of phospholipid transfer protein (PLTP) [6] and expression of HDL-binding molecules, such as CD36 [7] or SR-B1 [8], are all affected by diabetes. Furthermore, composition and functionality of HDL particles are also altered in diabetic patients [4]. Cholesterol efflux was reported to be impaired in diabetic patients partly due to the effect of increased concentrations of fatty acids on the ATP binding cassette transporters (ABCs) [9], or due to increased triacylglycerol content of HDL [10]. Earlier studies had also shown impaired cholesterol efflux when cells were incubated with plasma from diabetic individuals [11]. On the other hand we have recently demonstrated that cholesterol efflux to plasma from insulin-resistant individuals is greater than that of insulin-sensitive individuals [12]. Despite these advances, the specific mechanisms of RCT impairment and its contribution toward the pathogenesis of atherosclerosis in diabetic patients are still unknown.

Diabetes is characterised by chronic hyperglycaemia, which facilitates an accelerated non-enzymatic reaction between glucose and proteins to yield crosslinked proteins known as AGEs. Persistent hyperglycaemia and oxidative stress act to hasten the formation of AGEs not only in longlived proteins, but also in short-lived molecules such as apolipoprotein A-I (ApoA-I) [13, 14]. We [15] and others $[16,17]$ demonstrated that AGE modification impairs HDL functionality, which may contribute to the increased risk of atherosclerosis in diabetic patients. Most of these findings, however, were related to HDL modified in vitro and it is not clear if that level of HDL modification occurs in patients with uncontrolled and controlled diabetes. Further, the contributions of AGE modification of HDL and other AGEs in plasma to possible changes in RCT in diabetic patients are also unclear. This was investigated in a cross-sectional clinical study that compared diabetic patients with healthy controls. Because RCT could not be quantified directly in humans, we also investigated these questions more directly in two animal models. We found that the levels of AGE in human plasma in vivo did not impair variables of RCT nor did AGEs contribute to the impairment of RCT in the animal models. We therefore infer that other diabetes-related factors are more likely to be responsible for the impairment of RCT when that occurs in diabetes.

\section{Methods}

Patients Diabetic patients were recruited through the Diabetic Clinic at the Alfred Hospital (Melbourne, VIC, Australia). Inclusion criteria were: males and post-menopausal females, non-smokers, 55-75 years of age. All patients were taking metformin (850-2000 mg/day) and $50 \%$ of the patients were taking anti-hypertensive medications as well as medications to control other co-morbidities. A control group was recruited among volunteers, who were known not to have diabetes and were medication-free. All patients gave informed consent to the study, which was approved by the Alfred Hospital Human Ethics Committee (\#196-05).

Plasma and HDL Ten millilitres of fasting blood was collected into EDTA tubes and plasma was obtained by low-speed centrifugation. ApoB-depleted plasma was obtained after precipitation of ApoB-containing lipoproteins as described previously [18]. HDL $(1.083<\mathrm{d}<1.21 \mathrm{~g} / \mathrm{l})$ was isolated from $2 \mathrm{ml}$ of plasma by sequential centrifugation in $\mathrm{KBr}$ solutions.

Animals In the first model, male lepr ${ }^{(-)}$C57BL/KsJ ( $d b / d b$; Jackson Laboratories, Bar Harbor, ME, USA) or littermate lepr ${ }^{(++)} \mathrm{C} 57 B L / K s J$ mice were studied at 10 weeks of age. All mice were obtained from colonies maintained at the Alfred Medical Research and Education Precinct Animal Services (AMREP AS, Melbourne, VIC, Australia). Standard mouse chow and water were provided ad libitum.

In the second model, male $C 57 B L / 6$ mice were randomised to receive oral gavages with adenine $\left(1 \mathrm{mg} \mathrm{kg}{ }^{-1}\right.$ day $\left.^{-1}\right)$ or vehicle ( $0.5 \%$ methylcellulose) for 4 weeks ( $n=6$ /group). This results in marked tubulointerstitial fibrosis and nephron dropout, consistent histologically with changes seen in advanced chronic kidney disease [19].

Animal experimentation was approved by the AMREP Animal Ethics Committee (approval \#E/0814/2009/B); experiments were conducted in compliance with the 'Principles of laboratory animal care' (National Institutes of Health publication no. 85-23).

Ex vivo cholesterol efflux assay Cholesterol efflux was measured as described previously [18]. Briefly, THP-1 cells were incubated in serum-containing medium supplemented with $\left[{ }^{3} \mathrm{H}\right]$ cholesterol $(75 \mathrm{kBq} / \mathrm{ml})$ for $48 \mathrm{~h}$ and simultaneously activated with the liver $\mathrm{X}$ receptor (LXR) agonist TO901317 (final concentration $4 \mu \mathrm{mol} / \mathrm{l}$ ). Cells were then incubated for $24 \mathrm{~h}$ in serum-free medium in the presence of TO-901317. Plasma, ApoB-depleted plasma or lipoprotein-deficient plasma was then added to the final concentration of $1 \%$; alternatively, isolated HDL was added to a final concentration of $10 \mu \mathrm{g} / \mathrm{ml}$ of ApoA-I. Cells were incubated for $2 \mathrm{~h}$, after which aliquots of medium and cells were counted. The efflux was calculated as a proportion of 
radioactivity that moved from medium to cells (after subtracting efflux to medium without acceptors).

In vivo RCT assay Cholesterol efflux in vivo was measured using a model described by Rader and colleagues [20], with modifications described previously [21]. Briefly, RAW 264.7 macrophage cells were radiolabelled and loaded with cholesterol by incubating with $1.1 \mathrm{GBq} / \mathrm{ml}\left[{ }^{3} \mathrm{H}\right]$ cholesterol and acetylated LDL $(50 \mu \mathrm{g} / \mathrm{ml})$ for $48 \mathrm{~h}$. Cells were washed, incubated for $24 \mathrm{~h}$ in serum-free medium, harvested and resuspended in $0.15 \mathrm{~mol} / \mathrm{l}$ sterile saline at a concentration of $10^{7}$ cells $/ \mathrm{ml}$. Cells were injected intraperitoneally into male mice $\left(2 \times 10^{6}\right.$ cells containing $5 \times 10^{6} \mathrm{dpm}$ per mouse, $n=6 /$ group). After $24 \mathrm{~h}$, mice were killed and blood, liver and faeces collected. Aliquots of plasma were counted and cholesterol from liver and faeces was extracted according to Folch et al [22].

Plasma analysis Total cholesterol, HDL-cholesterol, LDLcholesterol and triacylglycerol levels in human and mouse plasma were measured using a colorimetric microassay (Wako, Osaka, Japan). $\mathrm{HbA}_{1 \mathrm{c}}$ levels in human plasma were measured by the Clinical Chemistry Department of the Alfred Hospital. Pre $\beta_{1}$-HDL, LCAT and cholesterol ester transfer protein (CETP) concentrations in the human plasma were measured by ELISA (Sekisui Medical, Tokyo, Japan). ApoA-I and ApoB levels in human plasma were measured using a COBAS Integra 400 Plus blood analyser. AGE levels in human plasma and isolated HDL were measured as carboxymethyl lysine (CML) using an assay from MBL International (Woburn, MA, USA) and AGE levels in mouse plasma were measured as described previously [23]. The amounts of labelled cholesterol and cholesteryl esters in mouse plasma were established after separating aliquots of mouse plasma using thin layer chromatography as described previously [24].

Statistics Means \pm SD are shown unless indicated otherwise. Statistical significance of the differences was assessed using unpaired Student's $t$ test. Pearson correlations (unadjusted) were applied to test associations between continuous variables. Continuous variables that were positively skewed were logarithmically transformed to derive approximate parametric data.

\section{Results}

Clinical study Twenty-six patients with established type 2 diabetes were compared with an equal number of controls in a cross-sectional study. Diagnosis of type 2 diabetes was based on elevated blood glucose levels using internationally accepted criteria. All patients were receiving metformin to control diabetes as well as a range of other medications for co-morbidities, but patients taking statins or fibrates were excluded from this group. In addition, a group of 17 patients taking statins was also recruited. Individuals in the control group were medication-free. Anthropometric and diseaserelated data are presented in Table 1. Control and diabetic groups did not differ in sex ratio and age, whereas the group of diabetic patients on statins was slightly older and had a higher proportion of females. Patients with diabetes had mean disease duration of 7 years and $\mathrm{HbA}_{1 \mathrm{c}}$ levels consistent with moderately controlled diabetes. Diabetic patients had significantly higher body weight, BMI and plasma AGE concentrations than controls.

Lipid-related variables for the three groups are shown in Table 2. As expected, patients with type 2 diabetes had lower levels of plasma HDL-cholesterol and ApoA-I and higher levels of plasma triacylglycerols. Plasma levels of total cholesterol, LDL-cholesterol, VLDL-cholesterol and ApoB were similar for the two groups; consequently the LDL-/HDL-cholesterol ratio was higher in patients with diabetes. Patients treated with statins had lower total cholesterol and LDL-cholesterol levels. Consistent with previous findings [12], mean pre $\beta_{1}$-HDL level was lower in diabetic patients. Furthermore plasma concentrations of LCAT were lower and CETP levels were higher in patients with diabetes.

The functionality of plasma and HDL of patients and controls toward RCT was then assessed in an ex vivo cholesterol efflux assay. Differentiated human monocyte-macrophages THP-1 activated with LXR agonist TO-901317 to upregulate expression of the $\mathrm{ABC}$ transporters were used as cholesterol donors. When whole plasma was used as an acceptor, the efflux of cholesterol to plasma from diabetic patients was $30 \%$ higher than plasma from controls $(p<0.001$, Fig. 1a). When plasma depleted of ApoB-containing lipoproteins was tested in a similar experiment, the average efflux was $60 \%$ lower than to full plasma, but again, the efflux to plasma from diabetic patients was $34 \%$ higher than to plasma from controls $(p<0.001$, Fig. 1b). In these experiments plasma was added at equal volumes despite plasma from diabetic patients containing less HDL-cholesterol and ApoA-I. When recalculated to equal ApoA-I concentration, the efflux to whole plasma and ApoB-depleted plasma from diabetic patients was, respectively, $47 \%$ and $45 \%$ higher.

Statins are frequently used to control dyslipidaemia in diabetic patients; therefore we also tested plasma from a smaller group of patients with diabetes treated with statins. The efflux to whole and ApoB-depleted plasma of patients from this group was $50 \%$ higher compared with plasma from individuals in the control group. There was no statistically significant difference in the efflux to plasma from diabetic patients treated and not treated with statins. A possible direct effect of another medication, metformin, was also investigated. Metformin added to plasma ex vivo 
Table 1 Anthropometric and disease-related data

${ }^{\mathrm{a}}$ Geometric mean $\pm \mathrm{SD}$

(Mann-Whitney $U$ test)

$* p<0.02$ vs control group

$* * * p<0.001$ vs control group

NA, not applicable

$\mathrm{ND}$, not determined

\begin{tabular}{|c|c|c|c|}
\hline Characteristic & Control & Diabetes (no statin) & Diabetes (with statin) \\
\hline$n$ & 26 & 26 & 17 \\
\hline Male/female & $20 / 6$ & $20 / 6$ & $8 / 9$ \\
\hline Age (years) & $56 \pm 13$ & $62 \pm 10$ & $66 \pm 10 *$ \\
\hline Weight (kg) & $80 \pm 12$ & $94 \pm 22 *$ & $92 \pm 16^{*}$ \\
\hline BMI $\left(\mathrm{kg} / \mathrm{m}^{2}\right)$ & $25.4 \pm 3.6$ & $32.1 \pm 8.8^{*}$ & $32.5 \pm 4.8^{*}$ \\
\hline Duration of diabetes (years) & NA & $7 \pm 6$ & $10 \pm 7$ \\
\hline $\mathrm{HbA}_{1 \mathrm{c}}(\% / \mathrm{mmol} / \mathrm{mol})$ & NA & $7.7 \pm 1.2 / 58 \pm 9$ & $7.1 \pm 1.2 / 54 \pm 9$ \\
\hline AGE in plasma $(\mu \mathrm{g} \mathrm{CML} / \mathrm{ml})^{*}$ & $0.74 \pm 0.29$ & $1.06 \pm 0.26^{* * *}$ & $1.9 \pm 0.81 * * *$ \\
\hline $\begin{array}{l}\text { AGE in plasma } \\
(\mu \mathrm{g} C M L / m g \text { protein })^{\mathrm{a}}\end{array}$ & $0.013 \pm 0.014$ & $0.022 \pm 0.008^{*}$ & $0.039 \pm 0.032 *$ \\
\hline $\mathrm{AGE}$ in $\mathrm{HDL}(\mu \mathrm{g} C M L / m g \text { protein })^{\mathrm{a}}$ & $0.31 \pm 0.37$ & $0.32 \pm 0.43$ & ND \\
\hline
\end{tabular}

at a concentration of $1.2 \mu \mathrm{g} / \mathrm{ml}$ [25] did not affect cholesterol efflux $(3.6 \pm 0.2 \%$ vs $3.5 \pm 0.5 \% p=0.9)$.

We then isolated pure HDL from plasma of individuals in control and diabetes groups and tested it in the same assay; equal amounts of HDL (ApoA-I) were added to the assay. The efflux of cholesterol to isolated HDL of diabetic patients was almost twice that of control individuals $(p<$ 0.001 , Fig. 1c). Further, the efflux capacity of several samples of lipoprotein-deficient plasma (LPDP) from the two groups was not significantly different between the groups (Fig. 1d). Thus, the capacity of plasma and HDL from patients with type 2 diabetes to support cholesterol efflux was higher than that from healthy individuals.

To gain an insight into a possible explanation for the elevated cholesterol efflux capacity of plasma and HDL in

Table 2 Plasma lipid variables

\begin{tabular}{llll}
\hline $\begin{array}{l}\text { Characteristic } \\
\text { Control }\end{array}$ & $\begin{array}{l}\text { Diabetes } \\
\text { (no statin) }\end{array}$ & $\begin{array}{l}\text { Diabetes } \\
\text { (with statin) }\end{array}$ \\
\hline $\begin{array}{c}\text { Total cholesterol } \\
(\mathrm{mmol} / \mathrm{l})\end{array}$ & $4.8 \pm 1.1$ & $5.0 \pm 0.9$ & $4.1 \pm 1.1^{*}$ \\
HDL-C (mmol/l) & $1.4 \pm 0.4$ & $1.1 \pm 0.4^{* * *}$ & $1.1 \pm 0.4^{* * *}$ \\
LDL-C (mmol/1) & $3.1 \pm 0.8$ & $3.1 \pm 0.8$ & $2.3 \pm 0.9^{* * *}$ \\
LDL-C/HDL-C & $2.4 \pm 0.9$ & $3.0 \pm 1.2^{*}$ & $2.1 \pm 1.1$ \\
VLDL-C (mmol/l) & $0.6 \pm 0.5$ & $0.8 \pm 0.4$ & $0.8 \pm 0.4$ \\
Triacylglycerols & $1.1 \pm 0.6$ & $1.7 \pm 0.8^{* * *}$ & $1.7 \pm 0.8^{* * *}$ \\
$\quad(\mathrm{mmol} / \mathrm{l})$ & $1.6 \pm 0.2$ & $1.4 \pm 0.2^{*}$ & $1.4 \pm 0.3^{*}$ \\
ApoA-I $(\mathrm{g} / \mathrm{l})$ & $0.8 \pm 0.2$ & $0.8 \pm 0.6$ & $0.7 \pm 0.2$ \\
ApoB $(\mathrm{g} / \mathrm{l})$ & $38.3 \pm 28.8$ & $21.7 \pm 14.8^{*}$ & $\mathrm{ND}$ \\
Pre $\beta_{1}$-HDL $(\mu \mathrm{g} / \mathrm{ml})$ & $9.7 \pm 2.5$ & $6.9 \pm 2.4^{* * *}$ & $\mathrm{ND}$ \\
LCAT $(\mu \mathrm{g} / \mathrm{ml})$ & $1.2 \pm 0.4$ & $1.4 \pm 0.4^{*}$ & $\mathrm{ND}$ \\
CETP $(\mu \mathrm{g} / \mathrm{ml})$ & & & \\
\hline
\end{tabular}

${ }^{*} p<0.05$ vs control group

$* * * p<0.001$ vs control group

HDL-C, HDL-cholesterol; LDL-C, LDL-cholesterol; ND, not determined; VLDL-C, VLDL-cholesterol diabetic patients, we considered associations between cholesterol efflux and other variables measured in this study. The associations were tested in the control group and the group of patients with diabetes not receiving statins. When cholesterol efflux to the whole plasma was considered for the combined group (all participants), it correlated with plasma CETP concentration, plasma ApoB, total cholesterol and total triacylglycerol levels (Table 3, electronic supplementary material [ESM] Fig. 1a-c). These relationships disappeared when cholesterol efflux to ApoB-depleted plasma was considered. Cholesterol efflux to ApoB-depleted plasma correlated with efflux to HDL in all groups $(r=0.459, p<0.02$
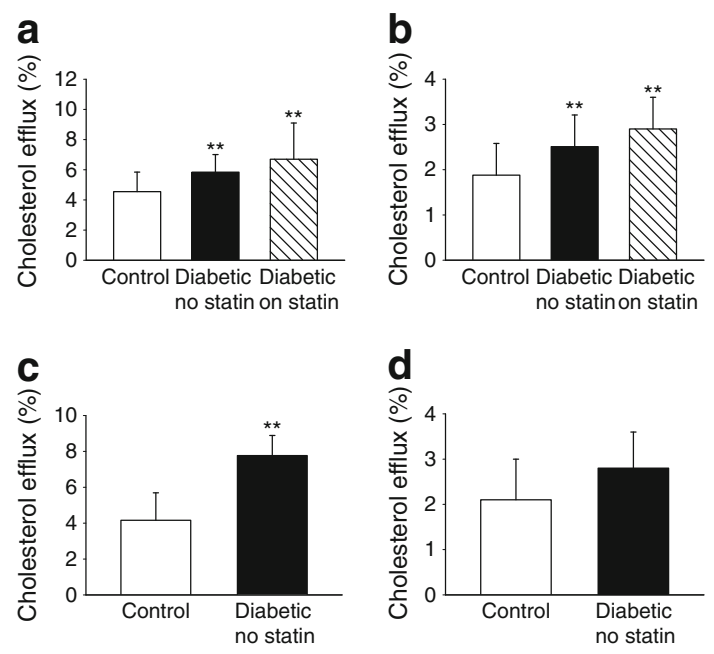

Fig. 1 Cholesterol efflux to whole plasma (a), apoB-depleted plasma (b), isolated HDL (c) and lipoprotein-deficient plasma (d). THP-1 cells were differentiated, labelled with $\left[{ }^{3} \mathrm{H}\right]$ cholesterol and activated with TO-901317 (4 $\mu \mathrm{mol} / \mathrm{l})$ as described in Methods. Cells were then incubated for $2 \mathrm{~h}$ with whole plasma (1\%) (a), apoB-depleted plasma (1\%) (b), isolated HDL (10 $\mu \mathrm{g} / \mathrm{ml}$ of apoA-I) $(n=13$ in each group) (c) and lipoprotein-deficient plasma in concentration of protein equivalent to $1 \%$ plasma ( $n=7$ in each group) (d). Cholesterol efflux is expressed as proportion of labelled cholesterol moved from cells to medium. $* * p<0.01$ vs control group 
Table 3 Univariate Pearson correlation coefficients

\begin{tabular}{|c|c|c|c|c|c|c|c|c|c|}
\hline $\begin{array}{l}\text { Cholesterol efflux } \\
\text { acceptor/group }\end{array}$ & $\begin{array}{l}\text { CETP } \\
(\mu \mathrm{g} / \mathrm{ml})\end{array}$ & $\begin{array}{l}\text { ApoB } \\
(\mathrm{g} / \mathrm{l})\end{array}$ & $\begin{array}{l}\mathrm{TC} \\
(\mathrm{mmol} / \mathrm{l})\end{array}$ & $\begin{array}{l}\text { TG } \\
(\mathrm{mmol} / \mathrm{l})\end{array}$ & $\begin{array}{l}\text { HDL-C } \\
(\mathrm{mmol} / \mathrm{l})\end{array}$ & $\begin{array}{l}\text { pre } \beta_{1}-\mathrm{HDL} \\
(\mu \mathrm{g} / \mathrm{ml})\end{array}$ & $\begin{array}{l}\mathrm{HbA}_{1 \mathrm{c}} \\
(\%)\end{array}$ & $\begin{array}{l}\mathrm{BMI} \\
\left(\mathrm{kg} / \mathrm{m}^{2}\right)\end{array}$ & $\begin{array}{l}\mathrm{CML}(\mu \mathrm{g} / \mathrm{mg} \\
\text { protein) }\end{array}$ \\
\hline Whole plasma combined & $0.326^{*}$ & $0.347 *$ & $0.315^{*}$ & $0.294^{*}$ & -0.076 & 0.007 & ND & -0.074 & 0.080 \\
\hline Whole plasma controls & 0.135 & $0.582 * *$ & 00.377 & 0.166 & 0.098 & $0.391 *$ & ND & -0.082 & -0.396 \\
\hline $\begin{array}{l}\text { Whole plasma } \\
\text { diabetic patients }\end{array}$ & $0.409^{*}$ & 0.182 & 0.247 & -0.021 & 0.215 & -0.301 & $-0.542^{* *}$ & $-0.545^{*}$ & 0.057 \\
\hline $\begin{array}{l}\text { ApoB-depleted } \\
\text { plasma combined }\end{array}$ & 0.244 & -0.202 & -0.057 & -0.020 & 0.059 & -0.272 & ND & 0.159 & 0.206 \\
\hline $\begin{array}{l}\text { ApoB-depleted } \\
\text { plasma controls }\end{array}$ & 0.341 & -0.239 & -0.058 & 0.066 & -0.014 & -0.264 & ND & 0.054 & 0.024 \\
\hline $\begin{array}{l}\text { ApoB-depleted plasma } \\
\text { diabetic patients }\end{array}$ & -0.001 & -0.246 & -0.120 & $-0.592 * *$ & $0.506^{* *}$ & -0.092 & -0.070 & -0.075 & 0.098 \\
\hline
\end{tabular}

${ }^{*} p<0.05$

$* * p<0.01$

HDL-C, HDL-cholesterol; ND, not determined; TC, total cholesterol; TG, triacylglycerol

for combined group), but not with the efflux to the whole plasma $(p>0.2)$. In the control group the efflux to whole plasma correlated with ApoB and pre $\beta_{1}$-HDL, whereas in the diabetic group efflux correlated positively with CETP and negatively with BMI and $\mathrm{HbA}_{1 \mathrm{c}}$ (Table 3, ESM Fig. 1). The efflux to ApoB-depleted plasma from diabetic patients correlated positively with ApoA-I and HDL-cholesterol and duration of diabetes, and negatively with plasma triacylglycerol level (Table 3); these correlations were not found in controls (Table 3). Importantly, there was no significant correlation between cholesterol efflux and plasma concentration of CML (Table 3), nor with plasma levels of LCAT (not shown) in any group and for any acceptor.

Another interesting finding was that plasma HDL level in the combined group correlated positively with plasma LCAT level $(r=0.325, p<0.02)$ and there was a trend for a negative correlation with plasma CML level $(r=0.277, p=$ 0.06 ); whereas plasma pre $\beta_{1}$-HDL level correlated positively with LCAT $(r=0.320, p<0.02)$ and negatively with plasma CETP level $(r=-0.354, p<0.01)$.

Animal studies To further investigate a connection between AGE and RCT we used two animal models. The first model was the $d b / d b$ mouse. These mice have been extensively used to study type 2 diabetes including diabetes-induced dyslipidaemia [26]. In contrast to humans with type 2 diabetes, $d b / d b$ mice have elevated levels of HDL [26]. The development of diabetes in these mice has several phases, with AGE levels being not elevated until the final stage characterised by hypoinsulinaemia and increasing hyperglycaemia [27]. The second model was that of chronic kidney failure induced by 4 weeks of treatment with adenine [28, 29]. The subsequent uraemia is associated with high AGE levels without hyperglycaemia and within a metabolic milieu dissimilar to diabetes. Comparison of the two models allowed specific assessment of the effect of AGE modification separately from other possible modifications characteristic of each model.

Plasma levels of AGE and lipid-related variables for the mouse models are shown in Table 4. As expected, $d b / d b$ mice had elevated levels of total and HDL-cholesterol and triacylglycerol. AGE levels were similar in $d b / d b$ versus control $\left({ }^{+/+}\right)$mice. On the other hand, AGE levels were 1.5 -fold higher in uraemic mice compared with those without uraemia $(p<0.05)$, whereas levels of total and HDLcholesterol were similar and triacylglycerols levels were lower. Thus, the $d b / d b$ model provided a metabolic environment characteristic of type 2 diabetes, but without AGE elevation, whereas the uraemic model provided an environment with elevated AGEs, but without metabolic features of diabetes.

We used a well-established in vivo model of RCT that follows transfer of labelled cholesterol from RAW 264.7 mouse macrophages implanted into the peritoneal cavity to plasma, liver and faeces. The amount of labelled cholesterol was 2.6-fold lower in plasma, 2.9-fold lower in liver and 1.7 -fold lower in faeces in $d b / d b$ mice compared with control $\left({ }^{+/+}\right)$mice; there was no difference in the amount of labelled bile acids in faeces (Fig. 2a-d). We also investigated the possibility that some cholesterol may have been excreted in urine in diabetic mice, but none was found. These findings are consistent with severe impairment of RCT in $d b / d b$ mice despite apparently elevated HDLcholesterol and no elevation in AGE levels.

In contrast to $d b / d b$ mice, RCT in uraemic mice was not impaired when compared with the control mice: the amounts of labelled cholesterol in plasma, liver and faeces were similar between uraemic and control mice (Fig. 2e-h), 
Table 4 AGE and plasma lipids in mouse strains

\begin{tabular}{lllllll}
\hline & $+/+(n=6)$ & $d b / d b(n=6)$ & $p$ value & Control $(n=6)$ & Renal failure $(n=5)$ & $p$ value \\
\hline AGE (mmol CML/mol lysine) & $60.2 \pm 14.6$ & $57.8 \pm 19.5$ & 0.9 & $39.1 \pm 5.9$ & $59.7 \pm 5.1$ & 0.04 \\
Total cholesterol (mmol/l) & $2.9 \pm 0.1$ & $4.0 \pm 0.2$ & 0.001 & $3.3 \pm 0.2$ & $3.2 \pm 0.2$ & 0.6 \\
HDL-C (mmol/l) & $2.4 \pm 0.1$ & $3.1 \pm 0.1$ & 0.001 & $2.8 \pm 0.1$ & $2.4 \pm 0.2$ & $1.1 \pm 0.1$ \\
Triacylglycerols (mmol/l) & $2.1 \pm 0.1$ & $4.7 \pm 0.6$ & 0.003 & $1.4 \pm 0.1$ & 0.15 \\
\hline
\end{tabular}

HDL-C, HDL-cholesterol

and there was no cholesterol excreted into urine. This finding suggests that increased AGE per se is not responsible for the impairment of RCT.
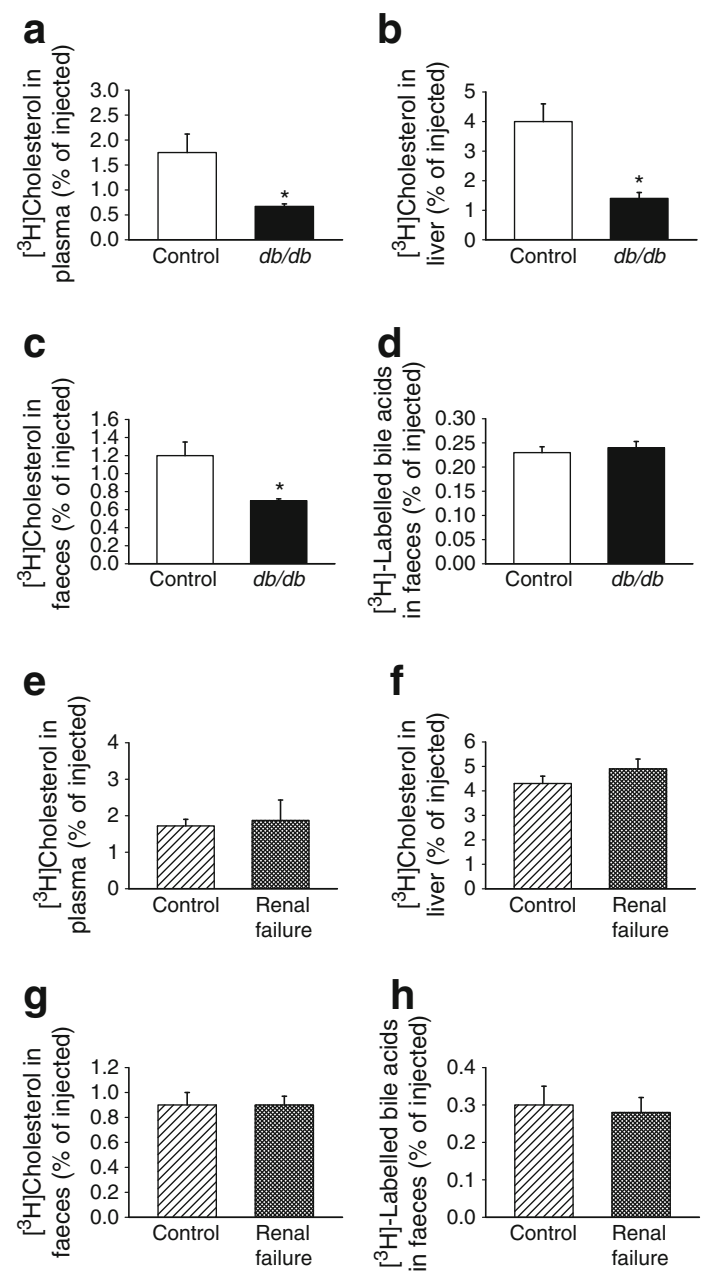

Fig. 2 In vivo RCT in $d b / d b$ vs control mice (a-d) or mice with renal failure vs control mice (e-h). RAW 264.7 macrophages were labelled with $\left[{ }^{3} \mathrm{H}\right]$ cholesterol, loaded with acetylated LDL and transplanted into an intra-peritoneal cavity of mice. (a-d) Experiment with $d b / d b(n=6)$ versus control $\left({ }^{+/+}\right)(n=6)$ mice; $(\mathbf{e}-\mathbf{h})$ experiment with uraemic $(n=5)$ versus normal C57B16 mice $(n=6)$. (a) and (e) show the amount of $\left[{ }^{3} \mathrm{H}\right]$ cholesterol in plasma, (b) and (f) show the amount of $\left[{ }^{3} \mathrm{H}\right]$ cholesterol in liver, (c) and (g) show the amount of $\left[{ }^{3} \mathrm{H}\right]$ cholesterol in faeces and (d) and (h) show the amount of $\left[{ }^{3} \mathrm{H}\right]$-labelled bile acids in faeces. ${ }^{*} p<0.05$ vs controls
We further investigated cholesterol esterification in all mouse models. As expected, most of labelled cholesterol was esterified after $24 \mathrm{~h}$ in both $d b / d b$ and control $\left({ }^{+/+}\right)$mice (Fig. 3a). There was a proportional decrease in both free and esterified cholesterol in $d b / d b$ compared with the control mice indicating no impairment in the plasma stages of RCT (Fig. 3a). In contrast, in uraemic mice there was a substantial reduction of cholesteryl esters and elevation of free cholesterol (Fig. 3b), and the cholesteryl ester/free cholesterol ratio was reduced from 1.6 to 0.24 . This finding is consistent with previously documented impairment of LCAT resulting from renal failure [30], but this, however, did not result in impairment of the overall efficiency of RCT in this model.

We also tested the capacity of plasma from all mouse models to support cholesterol efflux ex vivo in the same assay used in the clinical study. Consistent with the finding with human plasma, plasma from $d b / d b$ mice was $22 \%$ more efficient at supporting cholesterol efflux compared with plasma from control $\left({ }^{+/+}\right)$mice (Fig. 3c). However,
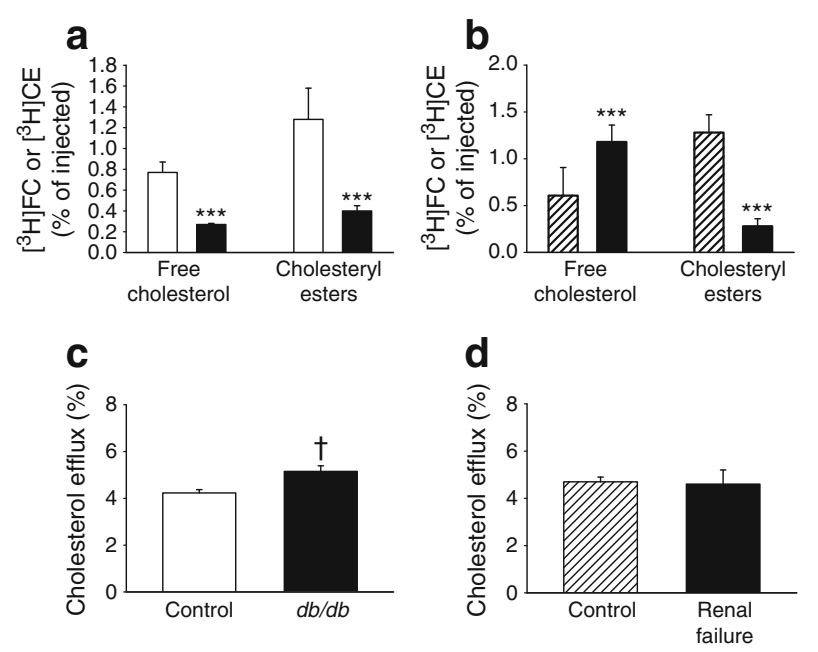

Fig. 3 Cholesterol esterification in vivo $(\mathbf{a}, \mathbf{b})$ and cholesterol efflux ex vivo (c, d) in two animal models. The amount of labelled free cholesterol and cholesteryl esters in plasma of $d b / d b$ ( $n=6$, filled bars) vs control $\left(^{+/+}\right)(n=6$, open bars $)$ mice (a) and uraemic $(n=5$, filled bars) vs control ( $n=6$, hatched bars) C57B16 mice (b). $* * * p<0.001$ vs controls. Cholesterol efflux from THP-1 cells to plasma (1\%) of $d b / d b$ vs control $\left({ }^{+/+}\right)$mice $(\mathbf{c})$ and uraemic vs control C57B16 mice $(\mathbf{d})$. ${ }^{\dagger} p<0.04$ vs controls 
when elevated HDL-cholesterol in $d b / d b$ mice was taken into account, and the efflux was normalised to plasma HDL-cholesterol levels, the difference was reduced and was no longer statistically significant $(4.7 \pm 0.2$ in control vs $4.4 \pm 0.1$ in $d b / d b$ mice, $p=0.2$ ) indicating that, in contrast to humans, a significant proportion of improved functionality of plasma toward cholesterol efflux was due to elevated HDL-cholesterol levels. Cholesterol efflux to plasma from uraemic mice was similar to that for plasma from control mice (Fig. 3d).

\section{Discussion}

AGE accumulation is a characteristic feature of diabetes and is thought to play an important role in the pathogenesis of diabetic complications, including cardiovascular disease. Glycation may affect RCT in two ways. Firstly, HDL and its main apolipoprotein ApoA-I may be subject to AGE modification despite its relatively short half-life in plasma. Advanced glycation of ApoA-I in vitro severely impaired multiple aspects of its functionality when measured in vitro $[15,16,31]$. Although AGE-modified HDL has been shown to be present in patients with uncontrolled diabetes associated with renal deficiency [15], it is unclear what levels of AGE-HDL are present in patients with moderate glycaemic control (the majority of patients seen in clinical practice) and how much this may affect HDL functionality. Secondly, the presence of other AGE-modified proteins such as albumin may affect RCT in the absence of modification of HDL itself. AGE-albumin impaired ABCA1, ABCG1 and SRB1-dependent cholesterol efflux in vitro [32-34] and ex vivo [35]. The contribution of AGEs to possible impairment of RCT pathway in diabetic patients is not clear.

In the clinical study we compared functionality of HDL from diabetic patients and controls with respect to cholesterol efflux. Glycaemia in these diabetic patients was moderately controlled but they nevertheless still had significantly elevated plasma AGE levels. The capacity of plasma, ApoB-depleted plasma and isolated HDL to support cholesterol efflux was significantly higher in diabetic patients. This is counterintuitive, as HDL functionality was expected to be impaired in diabetes. It must be noted that very few studies have investigated functionality of HDL isolated from plasma of patients with controlled type 2 diabetes, and findings in such studies have shown decreased [35, 36], unchanged [37, 38] or increased capacity of plasma to effect cholesterol efflux [12, 39].

To investigate possible reasons that may explain these observations, we studied the associations between cholesterol efflux and other variables measured in this study. One outcome of this analysis was that there was no association between plasma AGE levels and cholesterol efflux. This, combined with the observation that AGE levels in HDL were similar between the two groups with different efficiency for cholesterol efflux, makes it unlikely that AGE modification of HDL affects plasma capacity for cholesterol efflux.

Plasma levels of CETP and ApoB-containing lipoproteins most strongly correlated with changes in cholesterol efflux. This is consistent with our previous findings [12] and we have previously suggested that ApoB-containing lipoproteins may act as a 'sink' to which cholesterol taken up by HDL may be transferred, directly or by CETP after esterification, to improve the capacity of HDL to take up more cellular cholesterol [18]. We hypothesise that the reason why plasma and HDL from diabetic patients are more active in cholesterol efflux is through their higher levels of CETP. Higher activity of CETP would facilitate transfer of HDLcholesterol to ApoB-containing lipoproteins, reducing the amount of cholesterol in HDL, reducing HDL particle size and increasing their capacity to accept new cholesterol from cells even when ApoB-containing lipoproteins are removed. This is consistent with several reports that smaller particles are more active in cholesterol efflux [40, 41], and our recent finding of a correlation between the ability of plasma to support cholesterol efflux and CETP concentration [12]. It is, however, inconsistent with findings that functionality of HDL particles formed as a result of inhibition of CETP was not impaired [42, 43]. The only chemical modification of HDL known to increase its capacity to support cholesterol efflux is oxidative tyrosilation [44]; this was not tested in this study.

A limitation of this study was that patients were not medication-free. A common treatment received by all patients with diabetes was metformin and metformin has been shown to restore the capacity of glycated HDL to effect cholesterol efflux [45]. We have deliberately chosen a group of patients with controlled diabetes, nonetheless there was a high level of AGE in their plasma and especially in HDL. Despite this, the functionality of HDL was increased at least with respect to influencing the efflux ex vivo, a finding inconsistent with a 'restoration' hypothesis. However, it was thought possible that metformin present in plasma could affect cells during the ex vivo cholesterol efflux assay; this possibility was ruled out in a direct experiment. Treatment with another commonly used medication, statins, was investigated directly and shown not to be responsible for elevation of cholesterol efflux, a finding consistent with our previous study [46].

In the animal studies, we compared mouse models of diabetes and of kidney failure. $D b / d b$ mice are a wellestablished model of type 2 diabetes [47]. The mice were studied at 10 weeks of age, when they have type 2 diabetes, characterised by high insulin and modest hyperglycaemia, but the AGE levels are not yet elevated. Despite that, RCT in these mice was severely impaired. The likely RCT step 
affected by the diabetic milieu was the capacity of cells to release cholesterol because the amount of transported cholesterol was reduced in all three compartments, plasma, liver and faeces, whereas the capacity of plasma of these animals to support cholesterol efflux ex vivo and esterification of cholesterol in vivo was not impaired. In contrast, RCT was unaffected in uraemic mice with elevated AGE levels. These mice showed impaired cholesterol esterification, a wellknown consequence of kidney failure [30], but this also did not affect overall RCT. Thus, diabetes in the absence of AGE elevation inhibited RCT, whereas elevation of AGE in the absence of diabetes did not affect RCT. These findings support our contention that AGEs do not have a role in impairing RCT in diabetes.

Overall, we hypothesise that AGE modification of HDL, at least to the degree seen in patients with moderately controlled type 2 diabetes, is insufficient to cause functional impairment of HDL to effect cholesterol efflux. Moreover, this capacity of HDL is greater in patients with diabetes due to cholesterol depletion of their HDL caused by higher activity of CETP. Modifications, including AGE modifications of other elements of RCT, such as capacity of cells to release cholesterol or capacity of liver to take up cholesterol from HDL and LDL, may be responsible for impairment of RCT seen in animal models and in some clinical trials.

Funding This study was supported by a grant from the National Health and Medical Research Council of Australia (APP526614) and in part by the Victorian Government's OIS Program. JGL was supported by National Health and Medical Research Council of Australia and National Heart Foundation of Australia. DS and JF are Fellows of the National Health and Medical Research Council of Australia.

Duality of interest The authors declare that there is no duality of interest associated with this manuscript.

Contribution statement HL and AH performed the experiments, contributed to data analysis and critically revised the paper for important intellectual content. JF and MT performed the experiments, contributed to their design and participated in drafting the article. JGL contributed to data analysis and critically revised the paper for important intellectual content. PN contributed to the design of experiments and data analysis and edited the paper. LAB recruited the patients, contributed to the design of experiments and edited the paper. DS designed and supervised the experiments and wrote the manuscript. All authors approved the final version of the article.

\section{References}

1. Haffner SM, Lehto S, Ronnemaa T, Pyorala K, Laakso M (1998) Mortality from coronary heart disease in subjects with type 2 diabetes and in nondiabetic subjects with and without prior myocardial infarction. N Engl J Med 339:229-234
2. Beckman JA, Creager MA, Libby P (2002) Diabetes and atherosclerosis: epidemiology, pathophysiology, and management. JAMA 287:2570-2581

3. Goldberg IJ (2004) Why does diabetes increase atherosclerosis? I don't know! J Clin Invest 114:613-615

4. Berthezene F (1996) Non-insulin dependent diabetes and reverse cholesterol transport. Atherosclerosis 124(Suppl):S39-S42

5. Kappelle PJ, de Boer JF, Perton FG et al (2012) Increased LCAT activity and hyperglycaemia decrease the antioxidative functionality of HDL. Eur J Clin Invest 42:487-495

6. Riemens S, van Tol A, Sluiter W, Dullaart R (1998) Elevated plasma cholesteryl ester transfer in NIDDM: relationships with apolipoprotein B-containing lipoproteins and phospholipid transfer protein. Atherosclerosis 140:71-79

7. Griffin E, Re A, Hamel N et al (2001) A link between diabetes and atherosclerosis: glucose regulates expression of CD36 at the level of translation. Nat Med 7:840-846

8. Ohgami N, Miyazaki A, Sakai M, Kuniyasu A, Nakayama H, Horiuchi S (2003) Advanced glycation end products (AGE) inhibit scavenger receptor class B type I-mediated reverse cholesterol transport: a new crossroad of AGE to cholesterol metabolism. J Atheroscler Thromb 10:1-6

9. Oram JF, Vaughan AM (2006) ATP-binding cassette cholesterol transporters and cardiovascular disease. Circ Res 99:1031-1043

10. Autran D, Attia N, Dedecjus M, Durlach V, Girard-Globa A (2000) Postprandial reverse cholesterol transport in type 2 diabetic patients: effect of a lipid lowering treatment. Atherosclerosis $153: 453-460$

11. Syvanne M, Castro G, Dengremont C et al (1996) Cholesterol efflux from Fu5AH hepatoma cells induced by plasma of subjects with or without coronary artery disease and non-insulin-dependent diabetes: importance of LpA-I:LpAII particles and phospholipid transfer protein. Atherosclerosis 127:245-253

12. Nestel P, Hoang A, Sviridov D, Straznicky N (2012) Cholesterol efflux from macrophages is influenced differentially by plasmas from overweight insulin-sensitive and -resistant subjects. Int $\mathbf{J}$ Obes (Lond) 36:407-413

13. Brownlee M (2001) Biochemistry and molecular cell biology of diabetic complications. Nature 414:813-820

14. Lapolla A, Brioschi M, Banfi C et al (2007) Nonenzymatically glycated lipoprotein Apo-AI in plasma of diabetic and nephropathic patients. Ann N Y Acad Sci 26:295-299

15. Hoang A, Murphy AJ, Coughlan MT et al (2007) Advanced glycation of apolipoprotein A-I impairs its anti-atherogenic properties. Diabetologia 50:1770-1779

16. Nobecourt E, Davies MJ, Brown BE et al (2007) The impact of glycation on apolipoprotein A-I structure and its ability to activate lecithin:cholesterol acyltransferase. Diabetologia 50:643-653

17. Duell PB, Oram JF, Bierman EL (1991) Nonenzymatic glycosylation of HDL and impaired HDL-receptor-mediated cholesterol efflux. Diabetes 40:377-384

18. Hoang A, Drew BG, Low H et al (2012) Mechanism of cholesterol efflux in humans after infusion of reconstituted high-density lipoprotein. Eur Heart J 33:657-665

19. Terai K, Mizukami K, Okada M (2008) Comparison of chronic renal failure rats and modification of the preparation protocol as a hyperphosphataemia model. Nephrology (Carlton) 13:139-146

20. Wang X, Collins HL, Ranalletta M et al (2007) Macrophage ABCA1 and ABCG1, but not SR-BI, promote macrophage reverse cholesterol transport in vivo. J Clin Invest 117:2216-2224

21. Mukhamedova N, Escher G, D’Souza W et al (2008) Enhancing apolipoprotein A-I-dependent cholesterol efflux elevates cholesterol export from macrophages in vivo. J Lipid Res 49:2312-2322

22. Folch J, Lees M, Sloane-Stanley GM (1957) A simple method for isolation and purification of total lipids from animal tissues. J Biol Chem 226:497-509 
23. Coughlan MT, Thallas-Bonke V, Pete J et al (2007) Combination therapy with the advanced glycation end product cross-link breaker, alagebrium, and angiotensin converting enzyme inhibitors in diabetes: synergy or redundancy? Endocrinology 148:886-895

24. Sviridov D, Fidge N (1995) Efflux of intracellular vs plasma membrane cholesterol in HepG2 cells: different availability and regulation by apolipoprotein A-I. J Lipid Res 36:1887-1896

25. Christensen MM, Brasch-Andersen C, Green H et al (2011) The pharmacogenetics of metformin and its impact on plasma metformin steady-state levels and glycosylated hemoglobin A1c. Pharmacogenet Genomics 21:837-850

26. Kobayashi K, Forte TM, Taniguchi S, Ishida BY, Oka K, Chan L (2000) The db/db mouse, a model for diabetic dyslipidemia: molecular characterization and effects of Western diet feeding. Metabolism 49:22-31

27. Shafrir E, Ziv E, Mosthaf L (1999) Nutritionally induced insulin resistance and receptor defect leading to beta-cell failure in animal models. Ann N Y Acad Sci 892:223-246

28. Yokozawa T, Zheng PD, Oura H, Koizumi F (1986) Animal model of adenine-induced chronic renal failure in rats. Nephron 44:230-234

29. Morishita Y, Ohnishi A, Watanabe M, Ishibashi K, Kusano E (2011) Establishment of acute kidney injury mouse model by 0.75\% adenine ingestion. Ren Fail 33:1013-1018

30. Liang K, Kim CH, Vaziri ND (2005) HMG-CoA reductase inhibition reverses LCAT and LDL receptor deficiencies and improves HDL in rats with chronic renal failure. Am J Physiol Renal Physiol 288:F539-F544

31. Nobecourt E, Tabet F, Lambert G et al (2010) Nonenzymatic glycation impairs the antiinflammatory properties of apolipoprotein A-I. Arterioscler Thromb Vasc Biol 30:766-772

32. Isoda K, Folco EJ, Shimizu K, Libby P (2007) AGE-BSA decreases ABCG1 expression and reduces macrophage cholesterol efflux to HDL. Atherosclerosis 192:298-304

33. Passarelli M, Tang C, McDonald TO et al (2005) Advanced glycation end product precursors impair ABCA1-dependent cholesterol removal from cells. Diabetes 54:2198-2205

34. Ohgami N, Nagai R, Miyazaki A et al (2001) Scavenger receptor class B type I-mediated reverse cholesterol transport is inhibited by advanced glycation end products. J Biol Chem 276:13348-13355

35. Zhou H, Tan KC, Shiu SW, Wong Y (2008) Cellular cholesterol efflux to serum is impaired in diabetic nephropathy. Diabetes Metab Res Rev 24:617-623

36. Cavallero E, Brites F, Delfly B et al (1995) Abnormal reverse cholesterol transport in controlled type II diabetic patients. Studies on fasting and postprandial LpA-I particles. Arterioscler Thromb Vasc Biol 15:2130-2135

37. Rashduni DL, Rifici VA, Schneider SH, Khachadurian AK (1999) Glycation of high-density lipoprotein does not increase its susceptibility to oxidation or diminish its cholesterol efflux capacity. Metabolism 48:139-143

38. Dullaart RP, Groen AK, Dallinga-Thie GM, de Vries R, Sluiter WJ, van Tol A (2008) Fibroblast cholesterol efflux to plasma from metabolic syndrome subjects is not defective despite low highdensity lipoprotein cholesterol. Eur J Endocrinol 158:53-60

39. de Vries R, Groen AK, Perton FG et al (2008) Increased cholesterol efflux from cultured fibroblasts to plasma from hypertriglyceridemic type 2 diabetic patients: roles of pre [beta]-HDL, phospholipid transfer protein and cholesterol esterification. Atherosclerosis 196:733-741

40. Moerland M, Samyn H, van Gent T et al (2007) Atherogenic, enlarged, and dysfunctional HDL in human PLTP/apoA-I double transgenic mice. J Lipid Res 48:2622-2631

41. Franceschini G, Calabresi L, Colombo C, Favari E, Bernini F, Sirtori CR (2007) Effects of fenofibrate and simvastatin on HDLrelated biomarkers in low-HDL patients. Atherosclerosis 195:385391

42. Matsuura F, Wang N, Chen W, Jiang X-C, Tall AR (2006) HDL from CETP-deficient subjects shows enhanced ability to promote cholesterol efflux from macrophages in an apoE- and ABCG1dependent pathway. J Clin Invest 116:1435-1442

43. Yvan-Charvet L, Matsuura F, Wang $N$ et al (2007) Inhibition of cholesteryl ester transfer protein by torcetrapib modestly increases macrophage cholesterol efflux to HDL. Arterioscler Thromb Vasc Biol 27:1132-1138

44. Francis GA, Oram JF, Heinecke JW, Bierman EL (1996) Oxidative tyrosylation of HDL enhances the depletion of cellular cholesteryl esters by a mechanism independent of passive sterol desorption. Biochemistry 35:15188-15197

45. Matsuki K, Tamasawa N, Yamashita M et al (2009) Metformin restores impaired HDL-mediated cholesterol efflux due to glycation. Atherosclerosis 206:434-438

46. Sviridov D, Hoang A, Ooi E, Watts G, Barrett PHR, Nestel P (2008) Indices of reverse cholesterol transport in subjects with metabolic syndrome after treatment with rosuvastatin. Atherosclerosis 197:732-739

47. Sharma K, McCue P, Dunn SR (2003) Diabetic kidney disease in the $\mathrm{db} / \mathrm{db}$ mouse. Am J Physiol Renal Physiol 284:F1138F1144 